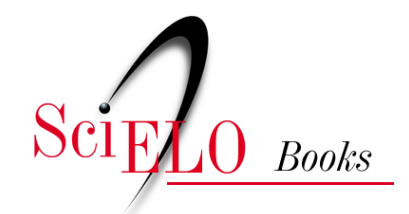

\title{
III. A elevação do Brasil a Reino Unido e a Aclamação de D. João VI
}

\author{
Juliana Gesuelli Meirelles
}

\section{SciELO Books / SciELO Livros / SciELO Libros}

MEIRELLES, J.G. A elevação do Brasil a Reino Unido e a Aclamação de D. João VI. In: A família real no Brasil: política e cotidiano (1808-1821) [online]. São Bernardo do Campo: Editora UFABC, 2015, pp. 43-54. ISBN: 978-85-68576-96-0. https://doi.org/10.7476/9788568576960.0004.

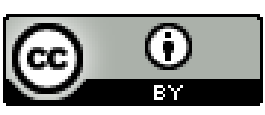

All the contents of this work, except where otherwise noted, is licensed under a Creative Commons Attribution 4.0 International license.

Todo o conteúdo deste trabalho, exceto quando houver ressalva, é publicado sob a licença Creative Commons Atribição 4.0.

Todo el contenido de esta obra, excepto donde se indique lo contrario, está bajo licencia de la licencia $\underline{\text { Creative Commons }}$ Reconocimento 4.0. 
III.

\section{A elevação do Brasil a Reino Unido e a Aclamação de D. JoÃo VI}

Em dezembro de 1815, Dom João, ainda Príncipe Regente, elevou o Brasil à condição de Reino Unido a Portugal e Algarves. Coincidentemente, 1815 também fora o momento em que Napoleão Bonaparte deixava de ser, definitivamente, uma ameaça à Europa. Portanto, pela ótica dos súditos portugueses, não havia razões plausíveis para que o Príncipe Regente e a família real continuassem a habitar a América. Além disso, o fato de o Rio de Janeiro ser a capital do Império Português e o Brasil deixar, institucionalmente, de ser Colônia de Portugal amedrontava os fiéis vassalos portugueses que, independente dos seus lugares na sociedade, mostravam-se cada vez mais insatisfeitos por estarem relegados a um plano político periférico. Em 1817, os ministros do Reino, Marquez de Borba, Principal Souza, Ricardo Raimundo Nogueira e João Antonio Salter de Mendonça enviavam uma carta a D. João. O conteúdo do documento registrava, exatamente, o profundo pesar da sociedade lusitana pela ausência da realeza.

Não devemos porém, Senhor, ocultar a V. Mage., por nossa honra e obrigação, o descontentamento geral de todos os seus fiéis vassalos pela demora de V. Magestade no Reino do Brasil, depois dos ordinários sacrifícios e heroicidades que fizeram, para conseguirem a salvação da Monarquia e a pronta restituição de V. Mage. à antiga sede da mesma ... E todos suplicamos a Deus Nosso Sr. que inspire a V. Mage., que se compadeça da necessidade que temos da Sua Augusta Presença nestes Reinos para a conservação dos mesmos, e nosso amparo e se digne pela sua misericórdia disportudo de maneira que V.Mage. possavir com todaa brevidade. (ANTT, Ministério do Reino. Governadores do Reino. Registro de Cartas ao Príncipe Regente, Livro 317, Carta 466, 17.3.1817, fl. 377)

Se os burburinhos e discussões das múltiplas vozes anônimas dos súditos da monarquia pelas ruas de Lisboa entoavam a canção do retorno da realeza e sua corte, existiam também aqueles súditos que demonstravam o desgosto da situação na qual se encontravam, como ocorreu em 1818. Com uma retórica própria aos moldes do Antigo Regime, o súdito português dirigia-se a El Rei, intitulando-se seu fiel vassalo. 
Agora por nossa desgraça, estamos vendo os louros voltados, o que vinha do Brasil, para Portugal, vai agora de Portugal para o Brasil ... e não somos nós por ventura, vassalos de V. M. para sermos tratados pela mesma maneira que são hoje os brasileiros? que tão felizes se acham e nós em tanta desgraça? há muito bem pode V. M. socorrer-nos, quando não, será por tempos, V. M. Rei de um Povo mendigo, e desgraçado. (Carta de hum fiel vassallo a El rei D. João VI, relatando o estado do Reino de Portugal sob o governo regencial e pedindo a volta se S. M." Documentos para a História da Independência, 1923: 6)

Ambos os registros refletiam, em graus díspares, um sentimento coletivo de angústia e desesperança do povo português, que ganhava cada vez mais força desde 1814, quando as discussões sobre o (in)evitável retorno da realeza começaram a germinar em terreno fértil. Desde então, pelas duas margens do Atlântico os bastidores do alto escalão político da monarquia lusobrasileira versavam sobre os prós e contras acerca das controvérsias inerentes à permanência ou ao regresso. Em $1^{\circ}$ de novembro de 1814, em umas das cartas que, cotidianamente, remetia aos familiares no Reino, o bibliotecário real Luís Joaquim dos Santos Marrocos refletia sobre a estadia prolongada da monarquia no Brasil. "Quanto a novidades, a que eu, como povo possa chegar, devo dizer a V. Mcê. que vai nascer uma fermentação oculta, que solapadamente vai minando em preparativos nossa ida para Lisboa: no Arsenal da Marinha se trabalha em aprestos para as embarcações de guerra; estas estão se concertando e aparelhando". Mais à frente, Marrocos contava sobre a chegada de oficiais na cidade que, segundo ele, vinham ao Rio para ajudar os poucos oficiais que havia e, portanto, fixavam residência por tempo "indeterminado". As notícias oficiais ou os boatos que corriam pela cidade sobre a volta da monarquia eram a sua maior preocupação, conforme dizia ele: “(...) no Público não há nada de novo: S.A.R não fala, nem consente que se fale nisso; e é essa a razão porque ninguém se prepara nem cuida e tal. Uns dizem que a 17 de dezembro é que vem a publicar-se nossa retirada, e que esta se verifica para março; outros que para todo o ano futuro; outros finalmente afirmam que esta não se efetua enquanto for viva S. Majestade, ou enquanto não se preencher o tempo deste último tratado com a Inglaterra. Daqui pode V. Mcê. concluir o quanto estamos às cegas neste ponto." A carta de Marrocos sinalizava para uma questão política central do Império Português: Qual deveria ser o lugar hegemônico do poder no mundo luso-brasileiro?

A necessidade da resposta dessa questão fundamental se fazia urgente. Os habitantes do Reino, já libertos do domínio francês, ansiavam por reaver a antiga centralidade de Portugal na conjuntura do Império. Já no Brasil, os súditos, particularmente aqueles que habitavam a capital do Rio de 
Janeiro, viviam sob uma conformação de amplos interesses que englobava um status político-econômico que não podia ser abolido, revertido ou mesmo ignorado de uma hora para a outra. Apesar dessa intensa polêmica, em 16 de dezembro de 1815 D. João elevou o Brasil a Reino Unido de Portugal e Algarves, o que sinalizava para a sua permanência em terras americanas.

Elevação do Brasil à Categoria de Reino - Carta de Lei do Príncipe Regente D. João

\section{(18 de Dezembro 1815)}

Dom João, por graça de Deus Príncipe Regente de Portugal e dos Algarves daquém e dalém-mar, em África, da Guiné e da Conquista Navegação e Comércio da Etiópia, Arábia, Pérsia, Etiópia, etc. Faço saber aos que a presente carta de lei virem, que tendo constantemente em meu real (?) ânimo os mais vivos desejos de fazer prosperar os Estados, que a Providência Divina confiou ao meu soberano regime e dando ao mesmo tempo a importância devida à vastidão e localidade dos meus domínios da América, a cópia e variedade dos preciosos elementos de riqueza que eles em si contêm e outros em reconhecendo quanto seja vantajosa aos meus fiéis vassalos em geral uma perfeita união e identidade entre os meus Reinos de Portugal, dos Algarves, e os meus domínios do Brasil, erigindo estes àquela graduação e categoria política, que pelos sobreditos predicados lhes deve competir, e na qual os ditos meus domínios já foram considerados pelos plenipotenciários das potências que formaram o Congresso de Viena, assim no Tratado de Aliança concluído aos oito de abril do corrente ano, como no tratado final do mesmo congresso: sou portanto servido, e me praz ordenar o seguinte:

- Que dada a publicação desta carta de lei o Estado do Brasil seja elevado à dignidade, preeminência e denominação de Reino do Brasil

- Que os meus Reinos de Portugal, Algarves, e Brasil formem dora em adiante um só e único Reino debaixo do título de Reino de Portugal, e do Brasil, e Algarves.

- Que os títulos inerentes à Coroa de Portugal, e de que até agora hei feito uso, se substitua em todos os diplomas, cartas de lei, alvarás, provisões, e atos públicos, o novo título de Príncipe Regente do Reino Unido de Portugal, e do Brasil e Algarves daquém e dalém-mar (...) Dada no Palácio do Rio de Janeiro, aos dezesseis de dezembro de mil oitocentos e quinze. ([Carta] Regitrada nesta Secretaria de Estados dos Negócios do Brasil, L. ${ }^{\circ}$ 2. ${ }^{\circ}$ de leis, alvarás, e Cartas Régias à fl.69. Rio de Janeiro, em 16 de dezembro de 1815 ).

Esse novo status político do Brasil que, consequentemente remodelava sua importância e centralidade dentro do Império Português, colocava os brasileiros em pé de igualdade com os portugueses. Os lusitanos, no entanto, 
reagiram mal a essa transformação. Tinha até quem dissesse que uma nuvem negra de desgosto geral cobriu os corações dos habitantes de Portugal, vendo no governo todas as disposições de reduzi-lo ao estado de Colônia, quando se elevava o Brasil à graduação de Reino (Anônimo, 1863: 147).

Silvestre Pinheiro Ferreira, funcionário de alta consideração da Coroa, foi um dos principais conselheiros de D. João nessa delicada questão de Estado, que estava diretamente ligada à manutenção da integridade imperial. Refletia o estadista português:

A questão de Estado, que se agita sobre o regresso da Corte de V.A.R para a Europa e sobre a qual V.A.R (...) se há dignado de ordenar-me, que diga o meu parecer, é sem dúvida, um dos maiores problemas políticos, que jamais soberano algum teve de resolver. Porquanto nele se não trata simplesmente de saber, em qual dos vastos domínios de sua real Coroa convém mais, que V.A.R se digne de fixar sua residência; trata-se de nada menos, que de suspender e dissipar a torrente de males, com que a vertigem revolucionária do século, o exemplo dos povos vizinhos, e a mal entendida política que vai devastando a Europa, ameaçam de uma próxima dissolução, e de total ruína dos estados de V.AR., espalhados pelas cinco partes do mundo, quer seja pela emancipação das colônias, no caso de V.A.R regressar para a Europa: quer seja pela insurreição do Reino de Portugal, se aqueles povos, perdida a esperança que ainda os anima. De tornar a ver o seu amado príncipe, se julgarem reduzidos à humilhante qualidade de Colônia.

(Proposta autografada sobre o regresso da Corte para Portugal e providencias convenientes para prevenir a revolução e tomar a iniciativa na reforma política, In: RIHGB, tomo 47 , parte I, p.2.)

Silvestre Pinheiro Ferreira defendia a posição de que D. João deveria permanecer na América sob o título de "Imperador do Brasil". Porém, o ministro atentava para os perigos dos descaminhos de uma possível separação política: impunha, no que se referisse ao poder executivo, que este deveria ser exercido exclusivamente por D. João, nos dois lados do Atlântico. A fragilidade do sistema imperial, contudo, escancararia suas fissuras durante o ano de 1817.

\section{A Revolução Pernambucana (1817)}

Entre os meses de março e maio, a província de Pernambuco viveu uma importante insurreição política, denominada pelos revoltosos de revolução pernambucana. 
A composição do movimento era de natureza absolutamente heterogênea. Negociantes de grosso trato, diversos proprietários de terras, homens do clero (muitos deles formados no Seminário de Olinda), pequenos sitiantes, homens livres, boticários e, inclusive, escravos e negros se opunham à opressão $\mathrm{e}$, consequentemente, às dificuldades financeiras impostas pela Corte desde a sua instalação, através do aumento dos tributos pagos por Pernambuco. Além disso, a péssima condição das tropas militares - mal pagas e mal alimentadas -, eram fatores que contribuíam para que os habitantes da província tivessem uma imagem despótica do Príncipe Regente. A ala de negociantes contrária à revolução era, na maioria, composta por portugueses residentes em Pernambuco, vinculados ao comércio lusitano, que detinham o monopólio de suas produções como o açúcar e o algodão.

Ao conseguirem dominar o Governo Provincial, os líderes do movimento - o negociante Domingos José Martins, Antônio Carlos de Andrada e Silva, Padre João Ribeiro, o magistrado José Luís Mendonça, o representante da agricultura Manuel Corrêa de Araújo, o militar Domingos Theotônio Jorge Martins Pessoa - instalaram um governo provisório cujas propostas básicas eram a proclamação da República, abolição de alguns impostos e a elaboração de uma constituição que estabelecesse a liberdade religiosa e de imprensa, bem como a igualdade de todos os proprietários perante a lei. No tocante à abolição do regime escravista, acenava-se para o fim gradual da escravidão, que ocorreria em um futuro ainda incerto. $\mathrm{Ou}$ seja, entre as noções de igualdade e propriedade, os revoltosos defendiam mais veementemente a segunda. Tal viés, contudo, apontava para outra questão de suma relevância: a noção de igualdade colocava em prática o rompimento dos laços de fidelidade com o rei. Em Preciso, nota escrita pelo líder José Luís de Mendonça, no dia 10 de março de 1817, em meio ao movimento, o magistrado refletia sobre as razões da queda do governo provincial: "Depois de tanto abusar da nossa paciência por um sistema de administração combinado acinte para sustentar as vaidades de uma corte insolente sobre toda a sorte de opressão de nossos legítimos direitos, restava caluniar agora a nossa honra com o negro labéu de traidores, aos nossos mesmos amigos, parentes e compatriotas naturais de Portugal; e era esta por ventura, a derradeira peça que faltava de se pôr à maquina política do insidioso governo extinto de Pernambuco". Ao relatar todos os acontecimentos ocorridos entre os dias 5 e 10 de março, Mendonça encerrava o escrito felicitando a nova pátria, os patriotas e exaltando, por fim, que acabasse "para sempre a tirania real". Já no poder, os insurgentes conquistaram o apoio das províncias de Paraíba e Rio Grande do Norte que, juntamente com Pernambuco, viveriam por mais de setenta dias sob 
um governo provisório que proclamava a independência da região, molamestra do movimento.

A República criava um novo contrato social, cujas representações, inclusive na mudança de tratamento pronominal das pessoas - introduziamse o uso de vós entre todos, o que os "igualava" e muito assustava os proprietários de terras -, apontava para a inauguração de um novo tempo histórico. O significado da bandeira republicana, nesse contexto, foi de grande simbologia.

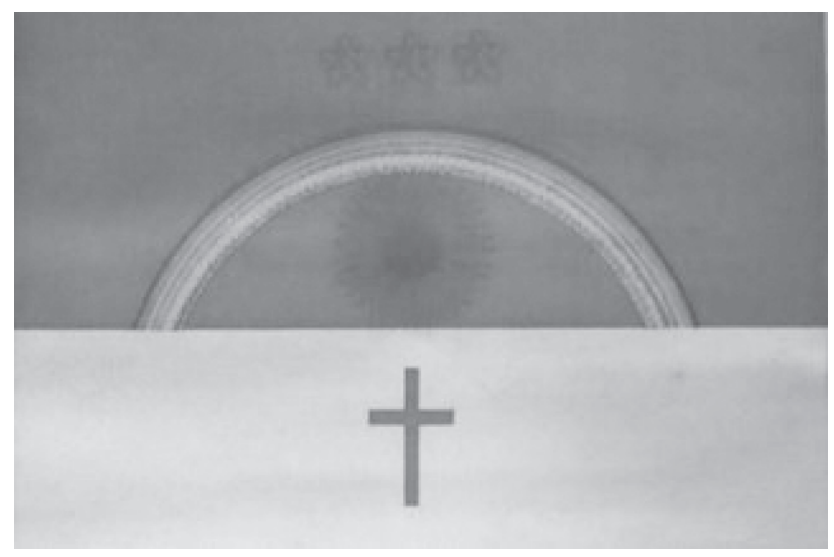

Bandeira da Revolução de 1817

A bandeira "era dividida ao meio, horizontalmente em duas cores, azul e branco. Tinha no branco uma cruz vermelha, sinal da religião cristã, uma alusão ao primeiro nome do Brasil - Terra de Santa Cruz -, e apontava o caminho da redenção", explica a historiadora Iara Lis Schiavinatto (1999: 71). Ainda sobre as cores e significados da bandeira, Schiavinatto ressalta que "na parte azul da bandeira, um sol esplendoroso vinha acompanhado de um arco-íris de três estrelas que simbolizavam as três províncias rebeldes. $\mathrm{O}$ sol significava os habitantes de Pernambuco que sob ele viviam e lembrava a justiça do astro que rege todo o universo" (Schiavinatto, 1999: 72).

O governo central não tardou em reprimir a revolução. As forças do Rio de Janeiro, comandadas por Luiz do Rego, sob a direção do presidente da capitania da Bahia, o Conde dos Arcos, articularam um forte bloqueio naval em Pernambuco. Ao adentrarem em Recife - dominando-a -, os representantes de D. João não hesitaram em ordenar aos homens da tropa real que adentrassem pelos caminhos da política do ferro e fogo. Uma das proclamações das tropas reais exigia que nenhuma reivindicação fosse atendida "sem que preceda como preliminar a entrega dos chefes da revolta, 
ou a certeza de sua morte", sendo, para isso, lícito "atirar-lhes a espingarda como a lobos".

A Revolução, no entanto, perdia força devido a fatores internos e externos que, pouco a pouco, minavam-na. Internamente, elementos conservadores e populares da capitania ajudavam a desmoralizar militarmente o movimento. Segundo as observações de Tollenare, viajante francês que se encontrava na província pernambucana durante a revolução, o povo vivia sem entusiasmo diante do ensaio democrático que se desenhava diante de seus olhos, pois percebia claramente que a sua situação não tinha melhorado como havia anunciado os líderes. Com o passar do tempo, as atitudes das lideranças republicanas passaram a ser questionadas, tanto que Domingos Theotônio já era considerado por muitos um ditador. A perda do idealismo da revolução colocava em cena outra perspectiva: o essencial era a salvação de cada um. Quando houve a entrada de cerca de 8 mil homens realistas em Recife, em 30 de abril, o desânimo já reinava na província. Em 20 de maio, exaltavase a vitória da contrarrevolução. Mais de 6 mil patriotas, contando-se aí escravos e libertos, retiraram-se para Olinda, deixando Recife deserta. Era dado restituir o poder monárquico à província rebelde, sob o comando de Luiz do Rego, novo governador da Pernambuco.

No mês de junho, enquanto Rego reafirmava o contrato soberano com a monarquia portuguesa, através da exposição pela cidade das cabeças e parte dos corpos dos conjurados, como ocorreu no caso da morte do Padre João Ribeiro, muitos súditos reais cumprimentavam o Príncipe Regente nos salões de São Cristóvão, felicitando-o - entre repiques de sinos, iluminações gerais e foguetes - pelo restabelecimento da ordem.

A Revolução Pernambucana foi destaque das notícias da Gazeta do Rio de Janeiro apenas em 14 de maio de 1817, quando as tropas realistas de D. João já estavam à frente do movimento.

Temos demorado por longo tempo a comunicar os nossos leitores quanto nos constava dos desastrosos sucessos, acerca da revolta de Pernambuco, não tanto pelo horror que sentíamos em semelhante acontecimento, ainda que bem desejaríamos não manchar com tal atrocidade as páginas da História Portuguesa, tão distintas pelo testemunho de amor, e respeito que os vassalos desta nação consagrarão ao seu Soberano nas ocasiões de maior apuro, e em distâncias muito remotas; mas para não adiantar fato, ou circunstância alguma em coisa por sua natureza tão odiosa de que não tivemos completa informação; e porque demais estando convencidos, assim como todos, de que os habitantes de Pernambuco, não podiam ter-se alienado até o ponto de perderem os sentimentos de fidelidade e obediência, que noutro tempo realçarão o seu caráter, não acertávamos, como pôde verificar a escandalosa ingratidão, que acabavam de manifestar. As notícias mais individuais, que 
ultimamente têm chegado, nos tiram desta incerteza, mostrando que na funesta rebelião de Pernambuco não teve parte a maioridade de seus habitantes; e não nos arrependemos por isso de uma demora que serviu para confirmar a persuasão em que estávamos e que tínhamos tanto a peito: sabe-se já com toda a evidência, que foi unicamente o resultado da trama de alguns malvados, que tomarão este expediente, para fugir à justa punição de seus crimes. (Gazeta do Rio de Janeiro, 1817, N. $^{\circ} 39$ ).

Paralelamente, em Lisboa, ocorria a descoberta da conspiração militar Gomes Freire contra a Dinastia de Bragança que fora abortada no mês de abril, antes mesmo de sua conflagração. A revolta tinha como objetivo a derrubada da supremacia militar inglesa sob o comando do Marechal Beresford e a implantação de uma monarquia constitucional que, na prática, desejava a restituição da figura real através de um Rei presente, justo e identificado com os anseios do seu povo, uma vez que D. João já era considerado por muitos "o mais perverso, e abominável subversor da pátria” (Memória sobre a Conspiração de 1817, vulgarmente chamada A Conspiração Gomes Freire; escrita e publicada por um português, amigo da justiça e da verdade, 1822: 52-53).

Um dos panfletos apreendidos contra o governo sintetizava as insatisfações dos revoltosos, que desejavam afastar os oficiais ingleses do poder e reorganizar a administração do Estado e das tropas portuguesas. Assim, conspiravam:

\section{Espírito Nacional}

Quem perde Portugal? O Marechal

Quem sanciona as Leis? O Rei

Quem são os executores? Os Governadores

Para o Marechal: hum punhal

Para o Rei: a Lei

Para os Governadores: os executores.

(Fonte: ANTT. Casa Forte. Ministério dos Negócios Eclesiásticos e da Justiça, M.22, fl. 204).

Beresford e os governadores do Reino exigiram a prisão dos revoltosos, abriram processo contra os envolvidos e enforcaram onze dos acusados, entre eles o general Gomes Freire de Andrade, considerado o líder do movimento.

Embora os movimentos ocorridos em 1817 contra o regime absolutista português vivenciassem universos e ideais políticos distintos entre si, em ambos se destacou a forte participação da Maçonaria, um fator preponderante e de grande importância na organização e desenrolar dos eventos políticos contestatórios que muito incomodavam o poder central. Porém, por mais 
que a monarquia luso-brasileira tivesse saído vitoriosa nos dois movimentos que contestavam o poder real, a partir de 1817 , ficava patente a crise do antigo regime português em ambos os lados do Atlântico que, três anos mais tarde, escancararia seus conflitos de forma irreversível, a partir de agosto de 1820, com a Revolução do Porto. A situação era tão delicada que escritos literários de vassalos de renome - como Estanislau Vieira Cardozo, segundo escriturário do Banco do Brasil e secretário do $1^{\circ}$ Regimento de Cavalaria de Milícias da Corte -, circularam pela cidade como uma forma de demonstração de fidelidade ao monarca.

Mas não te penes, Príncipe! Um momento

De perfídia, e desdouro não faz vulto

No quociente do século de glória.

Troveja o claro céu; benigno é sempre.

Cumpre porém olhar atento a esfera:

São das exalações os raios prole.

Enunciada esta insólita ousadia,

Tua alma nobre por extremo aflita,

Mais pelo que urge o nacional decoro

Que pelo que é de ti, que em fim és grande

Há de nadar de júbilo em torrentes,

Quando à porfia em turmas acorrerem

Povos fiéis ingênuos a oferecer-te

Os mais prezados bens - fortunas - vidas.

A ACLAMAÇão DE D. JoÃo VI (1818)

$\mathrm{O}$ ano de 1818 se mostraria bem diferente do anterior. Apesar de envolto em nuvens que desenhavam uma complexa situação política, o fato é que pela primeira vez na história do Velho Mundo um Rei era aclamado na América. A festa de aclamação de D. João VI, ocorrida no dia 6 de fevereiro, na Corte, foi uma das mais importantes manifestações do poder real no período joanino. Tratava-se de um momento sui generis marcado por simbologias e conexões políticas cuidadosamente arquitetadas pela elite luso-brasileira, cuja meta política era a consolidação de um Império luso-brasileiro com sede na América.

A cerimônia foi concebida como um espaço de legitimação do poder real que renovava a relação entre o Rei e seus súditos. $\mathrm{O}$ alcance da adesão maciça de todas as camadas da sociedade era um fator de fundamental relevância, sobretudo depois de a monarquia ter vivenciado momentos de 
grande fragilidade política em decorrência dos movimentos revolucionários de 1817. Dia 10 de fevereiro, quatro dias depois das festividades públicas, o redator da Gazeta Manuel Ferreira de Araújo Guimarães produzia o discurso da folha oficial com o objetivo de fixar a imagem de um povo que abençoa, apoia e adora o seu rei, irrestritamente. "Então salvaram as fortalezas e os navios surtos nesse porto, e se elevaram muitos fogos de artifícios, que arremedavam um regular fogo rolante com perto de dois mil tiros. Foi nesse afortunado momento que o imenso concurso de povo, que estava em frente à Varanda, e que atulhava as ruas contíguas, rompeu em unânimes vivas, que mostravam da maneira mais evidente o prazer que transbordavam no coração de todos."

As celebrações começaram às 9 horas da manhã, com todas as pompas dignas de uma festa da realeza. Os tiros de canhões e os repiques dos sinos indicavam a importância da data. "Toda a família real estava resplandecente de diamantes e de todas as vestimentas da Corte eram notáveis pela riqueza e elegância", observava o pintor e viajante francês J. B. Debret, ao acompanhar a chegada dos membros reais à missa solene, na Capela Real, que selava a magnitude do evento digno das circunstâncias, segundo o francês, pela eloquência política e religiosa (Debret, 1989: 65).

A questão central da aclamação, no entanto, estava intimamente associada a dois fatos políticos de suma importância para a manutenção da integridade da monarquia luso-brasileira. No que se refere à elevação do Brasil a Reino, consumada em dezembro de 1815, o festejo visava reafirmar a autonomia do Brasil dentro do Império Português, assim como imortalizar a figura de D. João VI como o monarca responsável por trazer a prosperidade e a civilização ao vasto continente do Brasil.

A escolha do dia 6 de fevereiro como data que oficializava sua coroação também foi um aspecto particularmente arquitetado por D. João. A associação com a fundação do Reino de Portugal rememorava as antigas tradições enraizadas em torno do princípio que legitimava a autoridade do direito divino dos reis em contraposição à concepção de soberania popular defendida pelos revolucionários na sedição pernambucana de 1817. Na prática, portanto, para além de a data da cerimônia se tornar uma resposta aos princípios republicanos dos revolucionários, ainda perpetuaria no calendário monárquico uma versão vitoriosa da história que solapava a visão dos "vencidos".

A festa de aclamação foi maciçamente financiada pelos negociantes de grosso trato como Fernando Carneiro Leão, Amaro Velho da Silva, Francisco José Guimarães, Francisco Pereira de Mesquita, João Rodrigues Pereira de Almeida entre outros. O grande dinheiro despendido nos festejos tinha como estratégia enaltecer a figura do rei, para assim, consolidarem suas órbitas de 
influência junto a D. João VI. Um dos arcos construídos - o arco do triunfo - realçava a imagem de um Rei ilustrado, cujo projeto era proteger e avançar as atividades comerciais e artísticas do Brasil, agora elevado a uma porção fundamental e civilizada do Império. Luís Gonçalves dos Santos, o Padre Perereca, descreveu com riqueza de detalhes as comemorações em torno da cidade, que toda iluminada, celebrava a coroação pelas igrejas, conventos e casas todas iluminadas cujas chamas e fogos de artifício demonstravam o amor e o prazer de seus fiéis vassalos (Santos, 1825: 632).

As luminárias e iluminações construídas por numerosos personagens endinheirados da cidade davam as diversas nuanças do regozijo que marcava o momento. O comendador Luís de Sousa Dias mandou construir um arco na porta da Alfândega que registrava a imagem da elevação do Brasil a Reino. Já a iluminação feita pelo tenente general José d'Oliveira Barbosa reafirmava o poder divino do Rei com os dizeres “Deus e o meu Rei”. Porém, as manifestações de apoio e fidelidade a D. João não chegavam apenas da parcela mais rica da sociedade. Bernardo Avelino Ferreira de Souza, um contemporâneo dos fatos, afirma que os mais pobres que viviam nos subúrbios também realizavam suas comemorações de acordo com suas possibilidades.

Apesar de tantas solenidades durante os três dias em que duraram os festejos, nem tudo foram flores. Quase um ano depois das sedições ocorridas em 1817, D. João ainda desconfiava da audácia das classes médias e populares, colocando em dúvida a lealdade de seu povo. "No primeiro e no segundo arco, onde eu me achava quase rente dele [D. João], pareceram-me provir de vagas suspeitas originadas de maus dizeres, que continuamente se estiveram a segredar em seu ouvido. Tive uma semelhante oportunidade de o observar, cerca de meia hora antes de seu início da cerimônia", comentava o viajante inglês John Luccock. O contato de Luccock com as classes médias e populares, no entanto, convencia-o de que não havia a menor razão para o temor, já que estava convicto "de que nunca houvera capital mais afeiçoada do que o Rio de Janeiro deste tempo" (Luccock, 1942: 379).

Para garantir a segurança pessoal do monarca e do cerimonial, a Intendência da Polícia distribuiu os soldados reais pela cidade. Munidos de cartuchos de pólvora, muitos deles se infiltravam em meio à gente miúda $\mathrm{e}$ cercavam o palácio para evitar possíveis badernas. Na multidão também foram implantados espiões para vigiarem os "elementos suspeitos" que poderiam atentar contra a vida do Rei. O olhar privilegiado e crítico de Luccock destacava os meios repressivos com que as tropas reais se precaviam diante do povo e, sobretudo, contra os estrangeiros. "Não era permitido a ninguém falar língua estrangeira em meio do povo. No momento em que um senhor natural de 
Veneza se dirigiu a mim em inglês, um soldado lhe ordenou rudemente que falasse português ou calasse a boca" (Luccock, 1942: 379).

A grande participação popular nessa festividade tão marcante não escondia as normas e etiquetas vigentes na sociedade de corte, há séculos enraizada e perpetuada pela monarquia portuguesa em datas comemorativas. O início da aclamação se dava com a entrada do Rei e seus acompanhantes que assistiam a uma oração pronunciada por um eclesiástico, responsável pela explicação dos motivos da realização da cerimônia. Na sequência, o Rei fazia seu juramento perante os dignitários, considerados testemunhas do ato, seguido pelo juramento dos presentes e, posteriormente, realizavase o beija-mão do soberano.

Todo esse cerimonial era regido por uma ordem hierarquia de acesso ao monarca. Primeiro, tinham vez os maiores representantes da nobreza portuguesa, em seguida tinham espaço os procuradores das cidades e vilas - sempre determinados por graus de importância - e, por último, era a vez do clero que, diferentemente dos demais estamentos, não tinha o privilégio de tomar a mão do Rei entre as suas; o que delineava os graus de influências e consequências políticas.

A aclamação popular, por outro lado, também marcava um momento importantíssimo da celebração. Era a ocasião em que acontecia a ovação dos súditos do Rei que, amontoados no Terreiro do Paço, legitimavam os laços políticos existentes entre o povo e o soberano. Logo após, o monarca e a Corte seguiam para a Capela Real, saudando o povo como exigia a tradição. Finalmente, às quatro horas da tarde, era chegada a hora da majestade aparecer publicamente pela primeira vez para os seus vassalos em todo o seu esplendor real.

Os lugares e hierarquias tanto dos súditos ao redor de El Rei quanto das instituições em destaque - como o senado da Câmara do Rio de Janeiro e os representantes da Universidade de Coimbra -, estavam bem delimitados e demonstrava a influência de cada um dos atores sociais nesse jogo de poder permeado por inúmeras representações e construção da memória coletiva.

Enquanto no Rio de Janeiro as iluminações pela cidade durante os festejos da aclamação demonstravam as manifestações de adesão do "povo" ao Rei e ao seu projeto político, em Portugal o silêncio, a indiferença ou as ausências nos festejos marcavam a revolta e a resistência ao mesmo momento. Houve até destruição de luminárias. Segundo o relato do português José Ribeiro Pinto, em Lisboa não se ouvia os vivas quando foi mostrado o retrato de D. João VI. 